\title{
Determination of candidate genes involved in schizophrenia using the whole-exome sequencing
}

\author{
Senormanci $\mathrm{O}^{1}$, Karakas Celik $\mathrm{S}^{2}$, Valipour $\mathrm{E}^{2}$, Dogan $\mathrm{V}^{3}$, Senormanci $\mathrm{G}^{1}$ \\ University of Health Sciences Bursa Yuksek Ihtisas Training and Research Hospital, Yildirim, \\ Bursa, Turkey. senorman_7@hotmail.com
}

\begin{abstract}
OBJECTIVES: We used the whole-exome sequencing to evaluate several genes suspected of being involved in the pathogenesis of schizophrenia.

METHODS: The study sample was composed of two families. In the first family, two siblings had schizophrenia, and the parents were healthy. In the second family, two siblings had schizophrenia, while the other sibling and the parents did not.

RESULTS: Indels were detected in some genes, including SPON1, GRIA3, SMAD5, PCLO, KMT2C, SRD5A2, SEMA3B, NCOR2, GPHB5, FAM174B, CLTCL1, and TMEM216. The insertion of three nucleotides (TGA) was detected in the sequence of the PCLO gene. The mutation resulted in the insertion of aspartic acid (Asp, D) in the amino acid sequence of the PCLO protein. Indels detected in SPON1, GRIA3, SMAD5, KMT2C, SRD5A2, SEMA3B, GPHB5, CLTCL1, and TMEM216 were shown to be frameshifting. Bioinformatics analysis showed that the indels in SPON1, GRIA3, SMAD5, KMT2C, SRD5A2, SEMA3B, NCOR2, GPHB5, FAM174B, CLTCL1, and TMEM216 had a damaging effect, while the indel in PCLO had a non-damaging effect on protein function. CONCLUSION: To the best of our knowledge, no previous studies have examined the relationship between the pathogenesis of schizophrenia and the gene mutations identified in this study (Tab. 1, Ref, 42). Text in PDF www.elis.sk. KEY WORDS: schizophrenia, genetic, whole-exome sequencing, family.
\end{abstract}

\section{Introduction}

Schizophrenia is a psychiatric disorder that causes chronic and significant problems worldwide, affecting $0.5 \%$ to $1 \%$ of the adult population (1). It is believed that genetic factors play an important role in the etiology of schizophrenia, and the heritability of schizophrenia is estimated to be approximately $80 \%$ (2). Genome-wide association studies (GWAS) are technologies that can identify small effect genes by examining single nucleotide polymorphism (SNP) and copy number variants by studying more than 1,000 patient's and control samples. These studies are very useful in cases of multiple genetic disorders such as schizophrenia (3). Although the common risk loci identified with GWAS cannot account for a large portion of the genetic risk (4), a multi-stage schizophrenia GWAS has been previously reported (5). Even if

${ }^{1}$ Department of Psychiatry, University of Health Sciences Bursa Yuksek Ihtisas Training and Research Hospital, Bursa, Turkey, ${ }^{2}$ Department of Molecular Biology and Genetics, Faculty of Sciences and Arts, Bulent Ecevit University, Zonguldak, Turkey, and ${ }^{3}$ Department of Psychiatry, Elazig Training and Research Hospital, Elazig, Turkey

Address for correspondence: O. Senormanci, University of Health Sciences Bursa Yuksek Ihtisas Training and Research Hospital, Mimar Sinan Mah. Emniyet Cad. 16310, Yildirim/Bursa, Turkey.

Phone: +902242955000, Fax: 0902242955497

Acknowledgement: This study was supported by Scientific Research Projects Commission of Bulent Ecevit University under project code number of 2014-29808450-01.
GWAS offers an important perspective for diseases, it has limitations, such as not being effective in the study of variations within communities, where the frequencies are at the lower ranges as well as being a time-consuming and costly method. Whole-exome sequencing (WES) methods are a new generation of sequencing methods used to study the mutations and diversities of rare diseases. The WES method is especially useful in developing clinical diagnoses and personalized disease risk profiles. Currently, the method is widely used due to its lower cost and the amount of time saved in obtaining results (6-8). To this point, very few studies have been conducted on schizophrenia using the WES method. However, one such WES-based study found that minor de novo mutations between N-methyl-D-aspartate receptor (NMDAR) complexes and glutamatergic post-synaptic proteins containing cytoskeleton-related proteins that regulate the plasticity of glutamatergic synapses play a role in the etiology of schizophrenia (9). In a case-controlled study conducted by Purcell et al., enriched gene sets were found to be voltage-gated calcium channels and signaling complexes created by activity-regulated cytoskeletonassociated scaffold proteins of post-synaptic density (PSD) (10). Somatic variations were investigated using the WES method for monozygotic twin schizophrenic patients and their parents in China. Although a somatic single nucleotide variation and two somatic additions/deletions were detected in the first stage of the study, no pathogenic somatic variants were detected in the Sanger sequencing (11). In Japan, an unc-13 homologous B (Caenorhabditis elegans) (UNC13B) gene was identified using the WES 
method on two schizophrenic patients and one healthy volunteer in a family with schizophrenia patients (12). Therefore, in order to enlarge previous studies, this research was aimed to define gene variants involved in schizophrenia by comparing individuals with schizophrenia and healthy individuals in the same family using a precise method over a short time period.

\section{Methods}

\section{Participant characteristics and evaluation}

This study was conducted on schizophrenia patients, who were regularly monitored psychiatrically in the Department of Psychiatry of the Medicine Faculty at Bülent Ecevit University, and on their first-degree relatives, who did not have any psychiatric disease. The patients' diagnoses were assessed by the Structured Clinical Interview for DSM-IV Axis I Disorders (SCID-I). The SCID-I is a structured clinical interview developed to determine the diagnosis of psychiatric disorders in the first axis according to DSM-IV $(13,14)$. All the patients had the paranoid schizophrenia subgroup criteria according to the DSM-IV-TR criteria (15). Ethics committee approval for the study was obtained from the Bulent Ecevit University Clinical Research Ethics Committee, protocol number of 2014-111-17/06. All the participants were informed about the study prior to enrolling in it.

Family 1 consisted of healthy parents and two siblings with schizophrenia. The first was a 36-year-old single female, who was a high school graduate and not working. She had been sick for an average of seven years; during that time, she was admitted to the psychiatric hospital six times. Her latest drug treatment consisted of clozapine $600 \mathrm{mg} /$ day, haloperidol $10 \mathrm{mg} /$ day, and biperiden 2 $\mathrm{mg} /$ day (Family 1 on the charts, Sibling 1). The second sibling was a 37-year-old single male, a primary school graduate, who was not working. He has been suffering from schizophrenia for 20 years and had been hospitalized many times in psychiatric hospitals. His latest drug treatment consisted of clozapine $700 \mathrm{mg}$ /day (Family 1, Sibling 2 on tabulations). Family 2 consisted of a healthy mother, a healthy child, and two schizophrenic siblings. One of the siblings was a 50-year-old male patient, a primary school graduate, who was not working. He had a 30-year history of illness with four admissions to the psychiatric hospital (Family 2, Sibling 2 on the charts). The last medications he used were palliperidone $12 \mathrm{mg} /$ day and quetiapine $200 \mathrm{mg} /$ day. The second sibling was a single 40 -year-old female, a primary school graduate, who was not working. She had been suffering from schizophrenia for 20 years and had had three admissions to the psychiatric hospital. The last medications she used were palliperidone $12 \mathrm{mg}$ /day and quetiapine $200 \mathrm{mg} /$ day (Family 2, Sibling 3 on the tabulations). The healthy control group did not have any DSM-IV diagnoses and no evidence of previous psychiatric referral.

\section{Whole-exome sequencing}

DNA samples were sheared into random fragments with Covaris technology, and the size of the library fragments were mainly distributed from $200 \mathrm{bp}$ to $300 \mathrm{bp}$. Then, adapters were ligated to both ends of the fragments. The DNA was amplified by ligation- mediated polymerase chain reaction (LM-PCR), purified, and hybridized to exome sequencing array. Non-captured fragments were washed out. The captured LM-PCR products were subjected to the Agilent 2100 Bioanalyzer and quantitative PCR to estimate the magnitude of enrichment. Each captured DNA sample was loaded onto Illumine Hiseq platforms. In this study, high throughput sequencing was performed for each library to ensure that each sample met the desired average sequencing coverage. Illumine base-calling software was used for base-calling with default parameters.

\section{Bioinformatics analysis}

Bioinformatics analysis was carried out on sequenced samples, which were unprocessed data generated by the Illumine machine. All the clean data of each sample were mapped to the human reference genome (GRCh37/HG19). Burrows-Wheeler Aligner (BWA) software was used to align computation and to map the reads (16, 17). To ensure an accurate variant calling, we followed the recommended best practices for variant analysis using the Genome Analysis Toolkit (GATK, https://www.broadinstitute.org/gatk/ guide/best-practices).

A 3-stage data filtering was performed to reduce the contamination on the sequenced fragments: (1) removing reads, which had an adapter sequence, (2) filtering out low quality calls (defined as having a Phred quality score equal to or less than 5) that were more than $50 \%$, and (3) removing error rates ("N" base) that were more than $10 \%$. Statistical analysis of the data and bioinformatics analysis were performed using this filtered, high quality data ("clean data"). After high-confidence indels were identified, the SnpEff tool (http://snpeff.sourceforge.net/SnpEff_manual.html) and the SIFT program (http://sift.bii.a-star.edu.sg/) were used as predictor programs. The SnpEff program was used to determine whether the indels had protein-coding changes that had affected amino acids. The SIFT program was used to predict whether an amino acid substitution had affected protein function based on sequence homology and the physical properties of amino acids.

\section{Results}

In this project, $50.39 \mathrm{Mb}$ target regions were captured, on which we performed variant calling. Total clean reads per sample were aligned to the human reference genome (GRCh37/HG19) using BWA $(16,17)$. On an average, $99.58 \%$ were mapped successfully. The strict data quality control (QC) was performed in the whole analysis pipeline for the clean data, the mapping data, the variant calling, etc.

In this research, 6,129 indels were detected, of which 928 were new indels. Of all indels, 380 were frameshifts, six were stoploss, six were startloss, and 56 were insertion. Of the all identified indels, 223 were only in patients and not in healthy family members.

In the present study, indels were detected in some genes, including SPON1, GRIA3, SMAD5, PCLO, KMT2C, SRD5A2, SEMA3B, NCOR2, GPHB5, FAM174B, CLTCL1, and TMEM216.

The insertion of TGA was detected in the sequence of the PCLO gene. The mutation resulted in insertion of Asp, D in the amino acid sequence of the PCLO protein. Indels detected in 
572-576

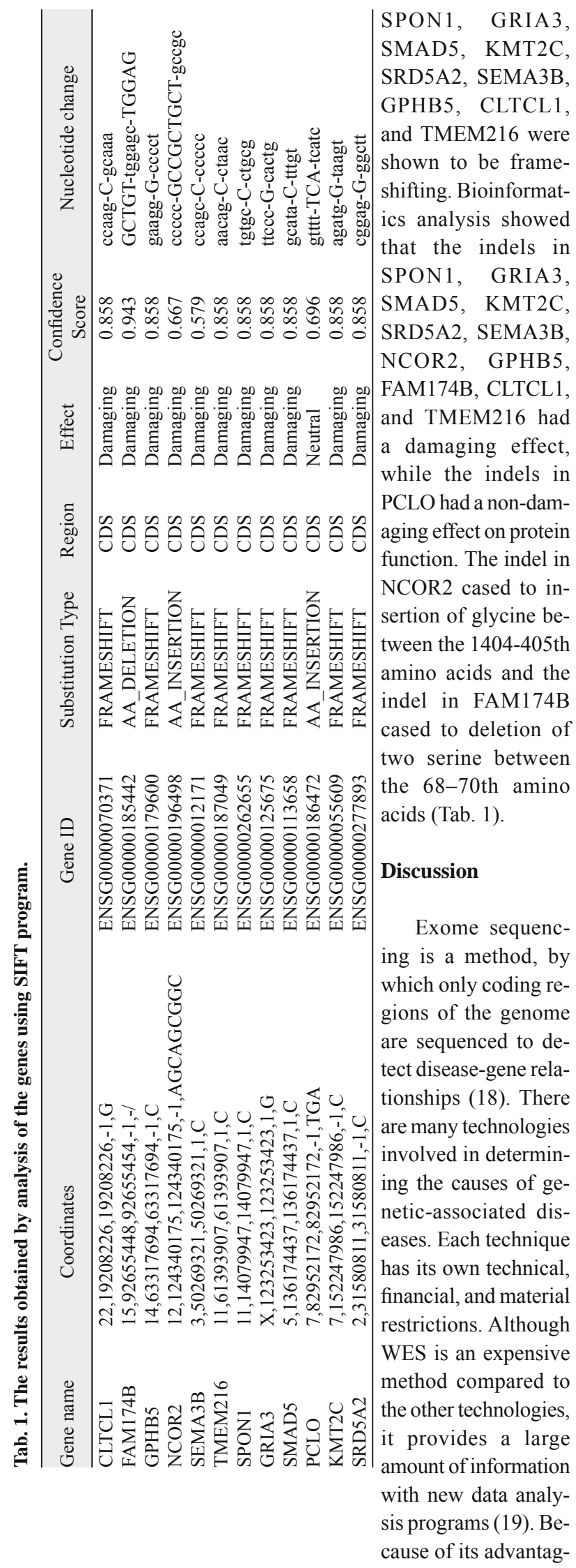

es and capabilities, we selected this method for use in this study. Some of the genes determined in this work have been known to be expressed in the brain, but there were not any published reports about their role in the pathogenesis of schizophrenia.

Common gene mutations of both sick and healthy individuals for each family were identified; then, a common pool of these gene mutations was made for both families. The number of genes carrying the insertion/deletion (ins/del) mutation that were obtained from the individual patients of both families was 200. By analyzing these genes, we were able to determine some genes that are involved in schizophrenia.

In the study performed by Jahanshad et al (2013), SPON1 variants were detected in rs 2618516 on chromosome 11 (11p15.2). The variants have been shown to cause structural changes in the brains of the elderly and to be responsible for various levels of dementia. Further analysis suggested that this gene and its surrounding gene networks probably had a significant association with autism, developmental disturbances, and mental retardation. The spondin-1 protein, also called F-spondin, is encoded by the SPON1 gene (20). Spondin protein that is secreted by ventral plaque cells has been found to aid axonal targeting of nerve cells during embryonic development and is a protein containing six thrombospondin domains (807 amino acids), a reelin domain, and a spondin domain. Due to its important role in the axon nerve junction in embryonic development, it is thought that mutations in the gene (especially frameshift mutations that lead to complete protein dysfunction) may be related to schizophrenia (21). In our study, the addition of $\mathrm{C}$ in position 602 of the SPON1 gene was detected in the common gene pool of the patients. Therefore, SPON1 can be evaluated as a candidate gene for schizophrenia.

Previously, Northern blot analysis revealed the GRIA3 transcripts in fetal and adult brains (22). The CHRNA3 gene has been acknowledged to have associations with the clinical features of schizophrenia patients (23). Similarly, the results of this research showed that the CHG33 gene of schizophrenic patients had a "CTG" deletion between 67-69 nucleotides. It was shown that the GRIA3 gene in rats causes pharmacological and kinetic changes to L-glutamate or $\alpha$-amino-3-hydroxy-5-methyl-4isoxazolepropionic acid (AMPA) (24). Although the GRIA3 gene is considered to be a candidate gene for broad bipolar disorder and X-linked mental retardation (22), it has been reported to be associated with schizophrenia (25).

The genes in the glutamate neurotransmitter system could be considered the potential candidate genes for schizophrenia. The effect of the deficiency of the glutamate signaling pathway in schizophrenia is supported by the fact that there are many mutations at the post-synaptic proteins involved in the NMDR and AMPA receptor (AMPAR) signaling pathways $(9,10)$. In a systematic study of the AMPAR, GRIA3 was also found to be associated with schizophrenia in women (26). GRIA3 promoter methylation has been shown to be significantly increased in schizophrenia patients compared to the non-disease control group (27). In our study, an ins/del mutation was detected in the GRIA3 gene of schizophrenic patients. This mutation leads to frameshift. Unlike the promoter methylation, frameshift mutation leads to the production of nonfunctional 
proteins. Therefore, GRIA3 can be evaluated as a candidate gene for schizophrenia.

Previously, a study was conducted on 300 Bulgarian schizophrenic patients and 600 healthy relatives of the patients to identify susceptibility genes for schizophrenia on chromosome 5q31-32, which is known to be a risk locus for schizophrenia. As the result of the analyses, the SMAD5 gene was found to be one of the candidate genes related to the 5q31-32 linkage region (28). Similarly, in this research, the insertion of $C$ at position 1315-1316, which leads to SMAD5 frameshift, was detected in the common gene pool of patients.

Mutations in $\mathrm{H} 3 \mathrm{~K} 4 \mathrm{me}$ regulators were observed in neurodevelopmental disorders, such as schizophrenia. KMT2C (lysine methyltransferase $2 \mathrm{C}$ ) is one of the $\mathrm{H} 3 \mathrm{~K} 4$ me methyltransferases $(29,30)$. In this study, deletion of the KMT2C gene was detected in the common gene pool of patients.

In a meta-analysis of schizophrenia, in which synaptic plasticity is believed to play an important role, dysbindin-1 has been identified the primary indicator of susceptibility to schizophrenia (31). The DNAPK complex binds and phosphorylates dysbindin-1. Functional associations between dysbindin-1 and DNAPK may be associated with schizophrenia (32). In this study, insertion and deletion were detected in the DNAPK gene in the common gene pool of patients. Therefore, this result is in agreement with previous reports.

Dysfunction of the hypothalamus-pituitary-adrenal axis is involved in the development of schizophrenia. It is thought that cortisol metabolizing enzymes such as schizophrenia 5 alpha reductase have an increased systemic activity (33). In the case-control study of schizophrenic patients and a healthy control group, the study of free cortisol, free cortisone and its metabolites, and SNP in the urine revealed that the SNP of SRD5A2 was significantly found in the schizophrenic group (34). On animal models, 5 alpha-reductase inhibitors have been shown to have an antipsychotic-like effect (35). In our study, it was determined that $C$ was inserted between the 89-90 nucleotides in the SRD5A2 gene in the common gene pool of patients.

In this study, in addition to these genes, the following mutations were also detected: addition of $\mathrm{C}$ between the 81-82 nucleotides in the SEMA3B gene, addition of nine nucleotides (AGCAGCGGC) between the 5517v5518 nucleotides in the NCOR2 gene, insertion of $\mathrm{C}$ between the 156-157 nucleotides in the GPHB5 gene, deletion of the GCTCCA sequence between the 206-211 nucleotides in the FAM174B gene, and insertion of G between the 3602-3603 nucleotides in the CLTCL1 gene.

SEMA3B is thought to play an important role in the guidance of growth cones during neuronal development (36). Northern blot analysis revealed an increase in NCOR2 protein expression in the brain tissue of mice (37). It has been reported that the lactoferrin level of serum is high in schizophrenic patients and is not affected by antipsychotic treatment (38). PCR analysis revealed that the amount of GPHB5 protein increases in human brain tissues (39). In situ hybridization of human embryonic tissues revealed an increase in the expression of TMEM216 in the central nervous system (40). In the patient with behavioral problems, epilepsy, and autism spectrum disorder, chromosomal deletion was detected at a region including FAM174B and two other genes (41). It has been found that the expression of the CLTCL1 gene increases in the developing human brain after conception and is effective in nerve growth (42). Although the role of these gene mutations in the pathogenesis of schizophrenia is unknown, both proteins are detected in patients, but are not found in healthy individuals. Further research is needed on the role of these genes and the proteins synthesized by them in the pathogenesis of schizophrenia.

\section{References}

1. Girard SL, Gauthier J, Noreau A, Xiong L, Zhou S, Jouan L, DionneLaporte A et al. Increased exonic de novo mutation rate in individuals with schizophrenia. Nature Genet 2011; 43 (9): 860-863.

2. Merikangas KR, Risch N. Will the genomics revolution revolutionize psychiatry? Am J Psychiatry 2003; 160 (4): 625-635.

3. Levinson DF, Levinson MD, Segurado R, Lewis CM. Genome scan meta-analysis of schizophrenia and bipolar disorder part 1: methods and power analysis. Am J Hum Genet 2003; 73 (1): 17-33.

4. Purcell SM, Wray NR, Stone JL, Visscher PM, O’Donovan MC, Sullivan PF, Sklar $\mathbf{P}$ et al. Common polygenic variation contributes to risk of schizophrenia and bipolar disorder. Nature 2009; 460 (7256): 748-752.

5. Ripke S, Neale BM, Corvin A, Walters JT, Farh KH, Holmans PA, Lee Pet al. Biological insights from 108 schizophrenia-associated genetic loci. Nature 2014; 511 (7510): 421-427.

6. Ng SB, Turner EH, Robertson PD, Flygare SD, Bigham AW, Lee C, Shaffer $\mathrm{T}$ et al. Targeted capture and massively parallel sequencing of 12 human exomes. Nature 2009; 461 (7261): 272-276.

7. Metzker ML. Sequencing technologies - the next generation. Nat Rev Genet 2010; 11 (1): 31-46.

8. Bamshad MJ, Ng SB, Bigham AW, Tabor HK, Emond MJ, Nickerson DA, Shendure J. Exome sequencing as a tool for Mendelian disease gene discovery. Nat Rev Genet 2001; 12 (11): 745-755.

9. Fromer M, Pocklington AJ, Kavanagh DH, Williams HJ, Dwyer S, Gormley P, Georgieva $L$ et al. De novo mutations in schizophrenia implicate synaptic networks. Nature 2014; 506 (7487): 179-184.

10. Purcell SM, Moran JL, Fromer M, Ruderfer D, Solovieff N, Roussos P, O'Dushlaine C et al. A polygenic burden of rare disruptive mutations in schizophrenia. Nature 2014; 506 (7487): 185-190.

11. Lyu N, Guan LL, Ma H, Wang XJ, Wu BM, Shang FH, Wang D et al. Failure to identify somatic mutations in monozygotic twins discordant for schizophrenia by whole exome sequencing. Chin Med J 2016; 129 (6): 690-695.

12. Egawa J, Hoya S, Watanabe Y, Nunokawa A, Shibuya M, Ikeda $\mathbf{M}$, Inoue $\mathbf{E}$ et al. Rare UNC13B variations and risk of schizophrenia: Whole-exome sequencing in a multiplex family and follow-up resequencing and a case-control study. Am J Med Genet B Neuropsychiatr Genet 2016; 171 (6): 797-805.

13. First M, Spitzer R, Gibbon M. Structured clinical interview for DSMIV Axis I disorders, clinician version (SCID-CV). Washington (DC): American Psychiatric Press, 1997.

14. Özkürkçügil A, Aydemir Ö, Yildiz M. DSM-IV eksen I bozukluklari için yapilandirilmiş klinik görüşmenin Türkçe'ye uyarlanmasi ve güvenilirlik çalişmasi. İlaç ve Tedavi Dergisi 1999; 12 (4): 233-236. 
15. American Psychiatric Association. Diagnostic and statistical manual of mental disorders. 4th ed. (DSM-IV TR) translator; Köroğlu E. Ankara: Hekimler Yayin Birliği, 2000.

16. Li H, Durbin R. Fast and accurate short read alignment with BurrowsWheeler transform. Bioinformatics 2009; 25 (14): 1754-1760.

17. Li H, Durbin R. Fast and accurate long-read alignment with BurrowsWheeler transform. Bioinformatics 2010; 26 (5): 589-595.

18. Ng SB, Buckingham KJ, Lee C, Bigham AW, Tabor HK, Dent KM, Huff CD et al. Exome sequencing identifies the cause of a mendelian disorder. Nat Genet 2010; 42 (1): 30-35.

19. Kahvejian A, Quackenbush J, Thompson JF. What would you do if you could sequence everything? Nat Biotechnol 2008; 26 (10): 1125-1133.

20. Jahanshad N, Rajagopalan P, Hua X, Hibar DP, Nir TM, Toga AW, Jack CR Jr et al. Genome-wide scan of healthy human connectome discovers SPON1 gene variant influencing dementia severity. Proc Natl Acad Sci 2013; 110 (12): 4768-4773.

21. Nagae M, Nishikawa K, Yasui N, Yamasaki M, Nogi T, Takagi J. Structure of the F-spondin reeler domain reveals a unique beta-sandwich fold with a deformable disulfide-bonded loop. Acta Crystallogr D Biol Crystallogr 2008; 64 (Pt 11): 1138-1145.

22. Gécz J, Barnett S, Liu J, Hollway G, Donnelly A, Eyre H, Eshkevari HS et al. Characterization of the human glutamate receptor subunit 3 gene (GRIA3), a candidate for bipolar disorder and nonspecific X-linked mental retardation. Genomics 1999; 62 (3): 356-368.

23. Petrovsky N, Quednow BB, Ettinger U, Schmechtig A, Mössner R, Collier DA, Kühn KU, et al. Sensorimotor gating is associated with CHRNA3 polymorphisms in schizophrenia and healthy volunteers. Neuropsychopharmacology 2010; 35 (7): 1429-1439.

24. Sommer B, Keinänen K, Verdoorn TA, Wisden W, Burnashev N, Herb A, Köhler M et al. Flip and flop: a cell-specific functional switch in glutamate-operated channels of the CNS. Science 1990; 249 (4976): $1580-1585$.

25. Lipsky RH, Goldman D. Genomics and variation of ionotropic glutamate receptors. Ann NY Acad Sci 2003; 1003: 22-35.

26. Magri C, Gardella R, Valsecchi P, Barlati SD, Guizzetti L, Imperadori L, Bonvicini $\mathbf{C}$ et al. Study on GRIA2, GRIA3 and GRIA4 genes highlights a positive association between schizophrenia and GRIA3 in female patients. Am J Med Genet B Neuropsychiatr Genet 2008; 147B (6): $745-753$.

27. Kordi-Tamandani DM, Dahmardeh N, Torkamanzehi A. Evaluation of hypermethylation and expression pattern of GMR2, GMR5, GMR8, and GRIA3 in patients with schizophrenia. Gene 2013; 515 (1): 163-166.

28. Zaharieva I, Georgieva L, Nikolov I, Kirov G, Owen MJ, O'Donovan MC, Toncheva D. Association study in the 5q31-32 linkage region for schizophrenia using pooled DNA genotyping. BMC Psychiatry $2008 ; 8: 11$.

29. Shen E, Shulha H, Weng Z, Akbarian S. Regulation of histone H3K4 methylation in brain development and disease. Philos Trans R Soc Lond B Biol Sci 2014; 369 (1652).
30. Vallianatos CN, Iwase S. Disrupted intricacy of histone H3K4 methylation in neurodevelopmental disorders. Epigenomics 2015; 7 (3): 503-519.

31. Allen NC, Bagade S, McQueen MB, Ioannidis JP, Kavvoura FK, Khoury MJ, Tanzi RE et al. Systematic meta-analyses and field synopsis of genetic association studies in schizophrenia: the SzGene database. Nat Genet 2008; 40 (7): 827-834.

32. Oyama S, Yamakawa H, Sasagawa N, Hosoi Y, Futai E, Ishiura S. Dysbindin-1, a schizophrenia-related protein, functionally interacts with the DNA-dependent protein kinase complex in an isoform-dependent manner. PLoS One 2009; 4 (1): e4199.

33. Steen NE, Methlie P, Lorentzen S, Hope S, Barrett EA, Larsson S, Mork E et al. Increased systemic cortisol metabolism in patients with schizophrenia and bipolar disorder: a mechanism for increased stress vulnerability? J Clin Psychiatry 2011; 72 (11): 1515-1521.

34. Steen NE, Tesli M, Kähler AK, Methlie P, Hope S, Barrett EA, Larsson S et al. SRD5A2 is associated with increased cortisol metabolism in schizophrenia spectrum disorders. Prog Neuropsychopharmacol Biol Psychiatry 2010; 34 (8): 1500-1506.

35. Bortolato M, Frau R, Orrù M, Bourov Y, Marrosu F, Mereu G, Devoto P et al. Antipsychotic-like properties of 5-alpha-reductase inhibitors. Neuropsychopharmacology 2008; 33 (13): 3146-3156.

36. Gong S, Zheng C, Doughty ML, Losos K, Didkovsky N, Schambra UB, Nowak NJ et al. A gene expression atlas of the central nervous system based on bacterial artificial chromosomes. Nature 2003; 425 (6961): 917-925.

37. Ordentlich P, Downes M, Xie W, Genin A, Spinner NB, Evans RM. Unique forms of human and mouse nuclear receptor corepressor SMRT. Proc Nat Acad Sci 1999; 96 (6): 2639-2644.

38. Hällgren R, Venge $P$, Wistedt $B$. Elevated serum levels of lactoferrin and eosinophil cationic protein in schizophrenic patients. Br J Psychiatry 1982; 140 (1): 55-60.

39. Hsu SY, Nakabayashi K, Bhalla A. Evolution of glycoprotein hormone subunit genes in bilateral metazoa: identification of two novel human glycoprotein hormone subunit family genes, GPA2 and GPB5. Mol Endocrinol 2002; 16 (7): 1538-1551.

40. Valente EM, Logan CV, Mougou-Zerelli S, Lee JH, Silhavy JL, Brancati F, Iannicelli M et al. Mutations in TMEM216 perturb ciliogenesis and cause Joubert, Meckel and related syndromes. (Letter) Nature Genet 2010; 42 (7): 619-625.

41. Kamien B, Harraway J, Lundie B, Smallhorne L, Gibbs V, Heath A, Fullerton JM. Characterization of a $520 \mathrm{~kb}$ deletion on chromosome $15 \mathrm{q} 26.1$ including ST8SIA2 in a patient with behavioral disturbance, autism spectrum disorder, and epilepsy. Am J Med Genet A 2014; 164A (3): 782-788.

42. Nahorski MS, Al-Gazali L, Hertecant J, Owen DJ, Borner GHH, Chen Y-C, Benn CL et al. A novel disorder reveals clathrin heavy chain-22 is essential for human pain and touch development. Brain 2015; 138 (Pt 8): $2147-2160$. 